\title{
Life Strategies of the Parents of Children with Intellectual Disabilities in the Context of Mixed Social Situations
}

\author{
Jakub Niedbalski \\ University of Lodz, Poland
}

DOI: http://dx.doi.org/10.18778/1733-8077.17.1.11

\section{Keywords:}

Disability; Parents;

Children; Stigma;

Mixed Social

Situations

\begin{abstract}
This paper aims to analyze the phenomenon of the managing of the stigma of a child's disability by their parents. Using the concept of stigma by Erving Goffman, I point to its usefulness in understanding the management of stigma by parents of children with intellectual disabilities in the context of mixed social situations. The research utilizes qualitative techniques with special emphasis on unstructured interviews. The data analysis was performed following the procedures of the grounded theory. As studies have shown, parents of children with disabilities adopt various strategies and tactics during the encounters with other persons and institutions while dealing with everyday hardships.
\end{abstract}

Jakub Niedbalski, a sociologist, is a research and teaching staff member employed in the Department of Sociology of Organization and Management of the Institute of Sociology, University of Lodz. He specializes in the computer-assisted analysis of qualitative data, qualitative research methods, the sociology of disability, and the sociology of sport. He researches the social activation of people with disabili- ties, as well as on the situation of families with people with disabilities, including entities and institutions supporting them. He is the author of several dozens of scientific publications devoted to the issues of disability, social assistance, as well as the qualitative research methodology.

email address: jakub.niedbalski@uni.lodz.pl 


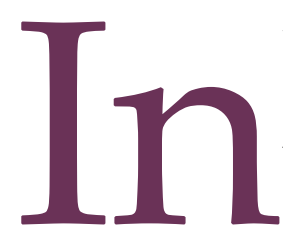

this work I have sought to learn about the ways parents of children with disabilities perceive the world around them, making sense of its certain elements, which, in turn, provides a basis for them to take action to shape their living space. ${ }^{1}$ I do not intend to address the issue of a child's disability from the perspective of a family tragedy, but to analyze how to deal with concealing and managing the openness concerning the child's dysfunction, which, according to parents, has a stigmatizing dimension and leads to social stigma. By using various strategies, the parents attempt to counteract the social stigmatization, and this is what I attempt to demonstrate in this paper. At the same time, I was interested in how the parents (mothers in particular, which was largely due to the fact that they were the ones who were much more often responsible for caring for a child with a disability and would, therefore, in many cases, be the parent who stayed at home, often giving up their job) deal with a situation of a change (which is often inevitable), which consists in progressing of the "visibility" of the dysfunction as their children mature and develop physically. I see the phenomenon of disability as a social construct which-taking on an embodied character-is becoming a source of stigma for parents with children with disabilities. Taking the above into account, the subject of my interest is the search for regularities in the interactive dynamics of the stigmatization process, for which mixed social situations (whether invoked in interactions or "present" in the strategic planning of activities by entities

\footnotetext{
${ }^{1}$ This text is part of broader research on the processual nature of changes taking place in multigenerational families, related to the growing up of children with intellectual disabilities. Therefore, the text is focused on the selected issue regarding the implementation of particular strategies and actions of parents in the context of mixed social situations-one of the leading analytical categories that emerged in the course of previous studies.
}

with damaged identity) are significant. Therefore, I used a concept crucial for understanding the dynamics of mixed social situations and the stigmatization process developed by Goffman-the concept of managing stigma (Goffman 1963).

\section{Review of Studies over the Situation of Families with Children with Disabilities}

Studies conducted with parents of children with disabilities show that a daughter's or son's dysfunction determines intra-family life, assigning new duties, functions, and tasks to each member, and often destroying its previous order (see, among others, Phyllis and Draine 1995; Hodapp, Glidden, and Kaiser 2005; Hodapp 2007). Scientific studies pay a lot of attention to the issues of parenthood and fulfilling the role of mothers (Docherty and Reid 2009) and fathers towards children (Heller and Arnold 2010), or the problems of motherhood and fatherhood of adults with disabilities (Hodapp, Glidden, and Kaiser 2005; Hodapp 2007). There is also research on the challenges of parental roles in the context of long-standing care and support in conditions of multigenerational families (Miltiades and Pruchno 2001). The interest of researchers is also stimulated by aging parents of adults with disabilities (as well as the persons with disabilities themselves), their challenges in everyday life, as well as the position, roles, and features of siblings of the adults with disabilities (Orsmond and Seltzer 2007). Seltzer, Floyd, and Greenberg (2005) analyzed the relations between the lifelong and long-standing disability of a child and the health condition of their parents.

Studies show that one of the effects of intellectual disability in a child may be the underestimated self-esteem of the parents. The sense of value that is experienced by parents raising mentally impaired 
children is often lost, which, in turn, leads to social exclusion (cf. Orsmond et al. 2003). The society avoids contact with individuals with disabilities and their families, being afraid of their differences, problems, and sometimes strange-because incomprehensible-behaviors, and this, in turn, leads to the so-called apparent integration, namely, we are in favor, unless it concerns us personally, for example, we support integration, but we do not want our child to be a part of an integration class (see: Barnes and Mercer 1997).

Studies exemplify that parents of a handicapped child apply several strategies in this context (Zakrzewska-Manterys 2010). First of all, they stress their sacrifice for the handicapped child and resignation from personal plans. Second of all, there is strong stress on their contribution to the main social course, at the same time emphasizing their own, total and undoubted, normality. The patterns of coping with the trauma of disability found among parents can be divided into direct reactions (they are involuntary) and long-term strategies (they are associated with greater awareness of choices) (Kościelska 1995:90-94). The first type of strategies include escaping-towards alcohol or work; deformation of perception-parents do not acknowledge the actual condition of their child, they contradict the facts; cognitive subordination-search for information about the causes, seeking for the guilty party; searching for support-from other people, sometimes to have the responsibility accepted by others; objectification of a child-into an object which certain activities are performed over. Longterm strategies cover three basic types. These are: leaving a handicapped child at the side of the main stream of life (a child and their disability is a kind of wound that is better not to touch or talk about); normalization of life (reaching a certain compromise that considers a child's needs and implementation of own plans); involvement in disability issues and making it a central point of one's life (cf. Zakrzewska-Manterys 2010:118).

The social support and the supporting factors may improve the flexibility of parents in dealing with the role, which is mentioned by Johnson (2000) and Phyllis and Draine (1995). The authors of the research emphasize that stress related to the situation of a long-standing role of a guardian for a child with a disability is a risk factor that may increase the probability of physical and mental consequences in parents. It is worth mentioning Freedman, Krauss, and Seltzer (1997), who analyzed the occurrence of a difference in four types of families, in terms of their characteristics, good mood, functioning, and formal support. Apart from data that suggest physical or mental issues in guardians that take care of and provide for the individuals with disabilities, survey research and clinical studies suggest that despite real psychological burdens there is also a certain positive impact from the situation of being a guardian-a parent of an adult child with mental disorders. The report and the results of research conducted by Aschbrenner, Greenberg, Allen, and Seltzer (2010) also showed the positive aspects of being a carer of a child with mental disorders. The authors pointed to existing relations between a parenthood role and experiencing positive life transformations while dealing with mental diseases of adult children.

Summing up, we can say that a family with a child with an intellectual disability fulfills the same functions that a family with a healthy child. However, the difference is in the conditions, implementing particular tasks, and in the intensity of their influences. A family that brings up a child with mental 
disability functions in the context of permanent overload. The distortion of the correct development of a child impacts the functioning of each family member and often poses a specific stress factor. Of course, the very presence of a child with limited mental capability within a family system does not make it dysfunctional at once. It is only the way in which families deal with a child's disability crisis in different situations and periods that determines their functionality or dysfunctionality.

\section{Research Methodology}

In this paper, the basis of the analyses carried out is an interpretative perspective-describing the world in the categories of reality construed in the course of symbolic interaction. According to the assumptions of the above paradigm, it has been assumed that individual actions are taken in specific situational and interactional contexts, thus resulting from the interpretation of a given event, situation, or phenomenon by a specific social actor. The definition of the situation is co-created and maintained in the course of interaction. Therefore, the reality of subjects appears as a configuration of certain meanings, the sense of which can be discovered as long as the experience of the people who produce them is captured. The leading theory explaining the analyzed phenomenon in this paper is the concept of stigma (Goffman 1963), which allows understanding the mechanism of the formation of unfavorable social attitudes and the barriers "separating" a person with a disability from society.

The research material in this study is the information obtained from parents, who experience significant transformations in their lives, related to the process of bringing up and taking care of their children with disabilities. These were, first of all, those families who have experienced a child's disability since birth (including prenatal and early childhood) and thus parents who have not experienced healthy parenthood in their parental "career" (I do not include situations where parents have more than one child and one of them is completely healthy).

Interviews were conducted with the representatives of such a category. The use of this type of data acquisition tool meant that each of the interviews was individualized. This means that the course of each interview was moderated on an ongoing basis and its content depended primarily on what issues were pointed out by the interviewee and how they emphasized the information appearing during the interview. The interviews were conducted in natural settings, mostly at the interviewee's place of residence, which was largely due to their situation related to the need to provide permanent care to family members with disabilities. Only a small part of the interviews was carried out outside the place of residence, which, in turn, was a result of limited dwelling conditions and the inability to speak to the interviewee. In any such case, the interviewee must have been able to ensure care for the child with a disability by other people (usually other family members).

All participants of the research were informed about the purpose and nature of the research, as well as about the terms and scope of adopting the data collected during the interviews. The research subjects could have their doubts clarified and ask questions allowing them to understand the essence of the research to its fullest extent.

In total, at this stage of research, 35 interviews were carried out between 2017 and 2019 among the parents of children with intellectual disabilities. The 
interviews were performed with 22 women and 13 men between 36 and 78 years of age. The interviews usually lasted from 1 to 3 hours. Before the analysis, the interviews were transcribed word-forword, preserving the details of the interviewees' utterances as faithfully as possible. All data were anonymized, which consisted of the permanent deletion of all information concerning first and last names, proper names, et cetera, or their replacement by other data which make it impossible to identify the participants.

Analysis and interpretation of the research material were conducted in compliance with the principles of the grounded theory methodology (Glaser and Strauss 1967; Glaser 1978; Strauss and Corbin 1990). Hence, the selection of subsequent cases for the research was of theoretical character (theoretical sampling), based on the constant comparative method. Thanks to theoretical sampling, a researcher, while collecting, encoding, and analyzing the materials, is making simultaneous decisions about where and what data to collect next (Glaser 1978:49-50; Strauss and Corbin 1990:177). While applying the constant comparative method in my search for other data, I attempted to choose cases that are both highly various and similar to each other, to grasp a maximum number of conditions differentiating the categories and their mutual relations (Glaser 1978:45-53; Charmaz 2006:74). This resulted in the fact that the researched group included the families taking care of people with intellectual disabilities of various degrees and types. The selection of cases lasted until theoretical saturation was achieved, that is, up to the moment when subsequent cases confirmed previous analytical findings (Glaser 1978:142).

Data analysis was supported by CAQDAS-Computer Assisted/Aided Qualitative Data Analysis
Software. The analytical and conceptual works were performed with NVivo software. The data were analyzed by adopting the functions implemented in this program, in a way corresponding to the requirements set forward by procedures of the employed research methods. The software also gave the possibility for continuous modification of all elements of the project as new information appeared. This made it possible to follow the data freely and the codes generated from them could have been changed quickly if they did not sufficiently reflect the current content of the collected material (Glaser 1978:4-5). In addition, NVivo enabled the creation of a structured code structure, that is, a category tree, in which certain modifications can be made. Apart from reflecting a code structure in the form of a category tree, NVivo allows creating relationships between particular categories. Using this function, it was possible to indicate the type of relationship and whether it was one-way or two-way, or simply to establish the very fact of its existence. The computer program, which was used to analyze the data, has special functions, which enabled the "verifying" of the hypotheses through scanning the parts of interviews and notes from observations. The software used was useful for improving theoretical concepts, as well as for creating and "consolidating" emerging hypotheses.

\section{The Importance of Stigmatization in the Context of Mixed Social Situations}

When the bearer of stigma and normals are in the same social situation, that is, in a direct physical co-presence both in conversation and even in some unorganized gathering, we are dealing with what Goffman (1963:44) calls mixed social situations. What is important is that interactions taking place in the context of mixed social situations involve 
a constant interpretation of the interactional partner's identity, an attempt to maintain it, or, on the contrary, to modify it. Such an action of a person with a discrediting feature is taken not only in the course of the interaction itself, but also at the level of its "planning." Since parents of children with disabilities usually have extensive biographical experience of being cast in the role of the stigmatized, in their case, the opening of each subsequent interaction is preceded by the anticipation of their public perception in terms of stigma.

Therefore, in the paper, I will treat disability as one of the individual's attributes, which becomes meaningful in different social situations. Disability, similarly to ability, are social constructs and as such, they depend, among other things, on the social context, the course of interactions, or the response of normals (Goffman 1963). I, therefore, look at disability through the prism of its contextuality, interactivity, and emergencies, as well as its multifactoriality and diversity.

The basis for interactions in the context of mixed social situations is the work on the stigma. It involves the management of stigma and is also referred to as work on self-presentation, because, in fact, the stigma treatments focus on the proper presentation of the person. An individual's situation depends largely on whether they recognize that their stigma is immediately recognizable by others (the situation of a discredited person) or is neither known nor recognized (the situation of a discreditable person) (Goffman 1963:34). In the case of a discredited position, there is a strong tension, manipulating it, adopting various tactics enabling or facilitating the transition between an assigned and real identity. In the discreditable position, on the other hand, an individual is not burdened with the accompanying tension resulting from the labeling character of the interaction, but strives to manipulate the information concerning whether, "To display or not to display; to tell or not to tell; to let on or not to let on; to lie or not to lie; and in each case, to whom, how, when, and where" (Goffman 1963:56). The manipulation of the stigma (in the case of discredited stigmatists) and the manipulation of information (in the case of discreditable stigmatists) is performed due to appropriate interactional tactics, which, in turn, depend on how the individual is perceived by others and whether they are known in their environment (cf. Błeszyńska 2001:92).

Both dimensions of the phenomenon under studyusing Goffman's (1963) terminology-build a dramatic performance by people with the disability stigma. For this reason, in the case of parents of children with disabilities who are discreditable, the main problem in interacting with normals is the tension created in social contacts, whereas in the case of discredited people, it is the proper management of information about their child's disability (Goffman 1963).

To understand the specifics of the interactional processes that make up the stigmatization process, it is crucial to recognize that the importance of mixed social situations is twofold. On the one hand, it is about the meaning that comes into play in the course of the interaction, in its dynamics, when it comes to a discrepancy between the attributed identity and the actual identity, which results in the awarding of stigma to the discredited party and the modification of the course of interaction by the inclusion of a certain type of tactics by that person (Goffman 1963). On the other hand, it is about the importance of mixed social situations and stigma in the case of a person with a discrediting characteristic, but in 
a way beyond any interaction with others. It manifests in the continuous building of the strategy before taking action, in the continuous consideration of communication options before opening an interaction, and in the planning of ways of controlling it, which is supposed to increase the chances of negotiating a satisfactory definition of the situation and social identity by a person with a discrediting characteristic. These processes are exemplified in the work undertaken by the bearer of stigma, which, according to the criterion of its purposefulness (or, in other words, the nature of the assumed effect), can be divided into the work on annulment, the work on highlighting (manifesting), and the work on suspending stigma.

\section{Work over the Annulment of Stigma}

The bearer of the stigma makes an effort to make their stigma unnoticeable to others and that their behavior does not deviate from the normals' behaviors. Therefore, the parents of children with "hidden" disabilities often try to control the information about the condition of their son or daughter. This happens because the very fact of the child's disability is hard to accept for them; it becomes even more burdensome when it begins to function as an element of their own identity. This is, first of all, due to a negative connotation of disability in a broader social context; but it may also result from an unclear status because not all ailments are generally recognized as credible health problems that entitle granting a status of a disabled individual (Kroll-Smith and Floyd 1997).

The cancellation of stigmata sometimes becomes a meaningful and complete interaction in which parents of children with disabilities take steps to alleviate the tension inherent in mixed social situ- ations. Such a work over the annulment of stigma assumes pushing it into the background of the interaction and is implemented by the following strategies: skipping and covering the stigma.

\section{Strategy for Skipping the Stigma}

While children with visible disabilities are imposed with a label by the environment, the children with hidden disabilities are labeled as a result of actions and decisions made by their parents in terms of covering or disclosing the stigma. Therefore, parents of children with disabilities that are not visible "at first glance" need to think carefully about how they will engage in active stigma manipulation (Carey 2013:142) and what actions they will want to take to properly manage information about their child's disability (Goffman 1963:78). Goffman's information management designed in this way is called passing and, as he writes, "Because of the great rewards in being considered normal, almost all persons who are in a position to pass will do so on some occasion by intent" (Goffman 1963:94).

When it comes to parents of children with disabilities, this strategy was implemented by means of catching-up and keeping your head down tactics. A common characteristic of both tactics is the work on omissions, which often takes the form of being "hyper-prepared," that is, exaggerating the correctness and meticulous preparation of the bearer of stigma. Thus, these tactics are a kind of attempt to compensate for certain deficiencies with other types of assets.

In the case of the catching-up tactics, it manifests itself in taking action from the perspective of their hyper-correctness, which consists of being overly correct, cultured in relation to other people who usually 
do not carry any stigma. At the same time, the bearer of the feature discrediting in interactions with others begins to feel a strong uncertainty about how they are perceived by their interactional partners, which sometimes leads to mental and emotional "self-disengagement" to avoid negative experiences (cf. Goffman 1963:45). Parents of children with disabilities are under constant stress, ready and vigilant to assess the impression of their child's disability others may have. They avoid any labeling errors.

Others don't understand us [the parents of children with disabilities]. Anyone who doesn't have the same experience won't understand what it means to be a parent of a disabled child. The worst part is that people are also quick to judge us. Generally speaking, it is as if others understand, sympathize with us, and treat us with forbearance. But, let only one person stand eye to eye with us and our child, they are about to change the standing. It doesn't take much because the understanding passes as soon as the direct contact appears, whether on the bus or in the park. When they hear a child screaming, they see them salivating, or waving their hands, there is a distance, and sometimes unpleasant words will also appear. [i.18.05] $]^{2}$

Parents of children with disabilities have only "one chance"-they must not be mistaken. They get one chance to present themselves, to improve their existence. Unless they use it skillfully, the chance is gone. There will not be another one, as they themselves emphasize. Meanwhile, people without children with disabilities have an infinite number of opportunities, which gives them the chance to

\footnotetext{
$\overline{{ }^{2} \text { I use indications }}$ of the cited fragments of my interlocutors' statements throughout the whole paper, where the letter " $\mathrm{i}$ " means an interview, the first figure indicates the year when the interview was carried out, and the last figure is the consecutive number of the interview. For example, the indication i.18.05 means that it was the $5^{\text {th }}$ interview carried out in 2018.
}

make mistakes and correct them. This responsibility for "one moment" reinforces a constant sense of tension, of being on standby, forcing the parents of children with disabilities to behave hyper-correctly, overly "normal," which sometimes only then becomes "abnormal."

Actually, we're being reviewed all the time. Wherever I go I get the interest, so I have to watch out, at least as much as I can, in my situation. But, one thing is certain, I will not disappear in the crowd, because I "stand out" thanks to my Józek [changed name], and wherever I go with him, there will always be some curious looks. [i.19.04]

The catching-up tactic also involves an approach based on the hyper-readiness of the parents, that is, an extremely meticulous preparation (sometimes also of the environment) for the various events to take place. Parents of children with disabilities are, in a way, in a state of constant, increased readiness and, at the same time, they constantly analyze everything that could potentially happen. Thus, situations that are completely natural, almost imperceptible, repetitive in the case of normals, fill the foreground of their lives as mediated carriers of stigma, sharpening their attention and vigilance (cf. Goffman 1963:128). They sometimes want to be perceived as "normal" by behaving "normally" to such an extent that they become artificial and exaggerate a number of behaviors, which, in turn, leads to secondary labeling, achieving an opposite goal to the intended one.

It's not so obvious because I've already experienced plenty of different situations, tried a lot, and felt it on my own skin. I'll put it this way, there is no single good practice that is always effective, because a lot depends on people, on other people and their attitudes. 
There are situations where it is better to pretend, and situations where you can be more direct and open. I'd say there's no rule in this regard. [i.19.01]

In addition to the catching-up tactic described above, the research participants also use the tactic of being transparent, interchangeably referred to as keeping your head down. The main mechanism here is for parents to try to pass the stigma by "blending into" their surroundings, not to be seen. Two main forms can be distinguished within the framework of this strategy, which, as in the case of the catching-up tactic, are in the form of "hyper," that is, they consist of exaggerating the correctness and preparing thoroughly for any encounter with normals. The former is hyper-sensitivity, while the latter can be described as hyper-subtlety.

Hyper-sensitivity seems to complement the above described "hyper" tactics, as it consists in particular in the care taken by the parent of a child with a disability to ensure that the child's dysfunction is not revealed, and thus the identity of the parent would not be at risk. In this case, it is about situations in which the disability of the child is not immediately visible, but also about the ones in which the disability is visible and yet not so obvious-due to practices related to the manipulation of the stigma of the disability-that parents manage to minimize the social effect of the stigma of the disability. It is also not uncommon for circumstances to occur where the true identity of the interactional partner is questioned. Goffman's words can be recalled here again (1963:81), according to which it fits into the mutual relations concerning mixed social situations in a suspicion awareness (Strauss and Glaser 1974), that is, situations in which there are signs containing specific information, sometimes revealing the discreditability of a person.
I think everybody wants to be considered normal, at least I think so. I'd say considered an ordinary person and parent. It's just that we [the parents of children with disabilities] are not like that. We are "different" because this is how people, who usually know little about us, see us. Am I actually "different?" I don't think so, at least I don't feel like it. Or rather, I want to feel like someone normal. That's why sometimes I just prefer not to talk about myself, about my child to other people. Then I don't feel like they give me this label of "the other." [i.17.04]

The parents feel that various mistakes or failures, which are, however, difficult to avoid, are immediately interpreted as a sign of the stigma of their daughter's or son's disability. Thus, the parents undertake continuous work on the behavior of both their child and their own. On the one hand, it consists of preventing various uncontrolled and abnormal behaviors of the child (e.g., unnatural movements or loud incomprehensible sounds), done due to their daughter's or son's dysfunction. On the other hand, it is constantly monitoring oneself and one's emotions in difficult and stressful situations, which results from the stigma of disability. In the case of parents, therefore, this is a work on emotions, especially as emotions which-being natural in the case of normal people-often become undesirable and quickly interpreted as inappropriate (e.g., what can be interpreted as behavior falling within the "norm" in the case of parents of fully capable children, can be considered as "degeneration" when it becomes a matter for parents of children with disabilities). Hyper-sensitivity is supposed to lead to "normality," but all these "normal" reactions (emotions) are under the social "magnifying glass." Hence, a parent as a bearer of stigma, while being censored, takes up work on "normal" emotions, which by definition seems to be a Sisyphean work. 
The parents of children with disabilities are aware that they represent a social group that is subject to a more stringent assessment, which does not apply to people without a discrediting characteristic.

I say that I always feel like I was a kind of an alien who fell from heaven having my face engraved with some slogans telling that I'm out of this world. It may be so because my world is different from the world of most people who have nothing to do with disabilities. That's why I'm not surprised that people don't understand me and treat me a little bit like a freak. It's the way I feel, but I guess I'm not the only one who feels that way because when I talk to other parents [of children with disabilities], they have similar experiences. [i.18.09]

Hyper-subtlety is another tactic that can be distinguished in the process of keeping your head down. It reveals such stigma bearers' behaviors that make the parents of children with disabilities attempt to control the emotions and thus not to show their nervousness, embarrassment, or dissatisfaction, among other things. It is, therefore, an activity that aims not to "burden" the parent with too much curiosity, interest, and sometimes expressing some dissatisfaction and disapproval on the side of normals who experience "disruption" of normal social interactions in contact with parents of a child with a disability. Hyper-subtlety can be especially observed in difficult moments due to the child's uncontrolled behaviors or the reactions of persons around them who often express their dissatisfaction, indignation, and sometimes unrestrained and tactless curiosity in a more or less direct and ruthless way.

It's like, on the one hand, the parents of children with disabilities try not to arouse any curiosity and unnecessary interest in themselves and their child, rather avoiding than exposing themselves to various difficult experiences in contact with the surroundings. On the other hand, it's also a way of how fully capable people act; when they don't know what to do or how to behave in a given situation, they make us feel transparent. This has its advantages and disadvantages as it gives more freedom and fewer misunderstandings, but it also tends to be tiring and frustrating when you feel you're not treated as a serious partner. [i.17.05]

What is more, there are some situations when the "normal" treatment of the stigma bearer starts to be interpreted as playing a game (usually due to the natural functioning in the suspicion awareness context), which, in turn, puts the normals in a relatively difficult position of completely losing track of what may be the best behavior in a particular situation. It is, therefore, an element of sentimental work, which, according to Strauss (Strauss et al. 1985:129-132), is an element of work based on calming emotions and involving the patient in various therapeutic and support activities. At the same time, parents themselves often point out that fully capable participants of the situation behave in this way because they feel embarrassed and do not know how to behave when they "discover" their child's disability (cf. Belzyt 2005).

Unfortunately, but it's often true that people aren't so good when [you] get to know them...I say this because I've experienced it more than once. When somebody doesn't know me, our situation, and my child, they treat us differently. Unfortunately, I experienced the way people treat us when they find out about the disability. There's either this artificial compassion, which I just don't like, or this gentle avoidance because they don't know how to behave. Anyway, it's just so unnatural and sad at the same time. [i.18.09] 
Summing up-the practices of hyper-correctness, hyper-preparation, proving usefulness and the mechanisms of hyper-sensitivity and hyper-subtlety implemented as a part of the tactics of keeping up and keeping your head down seem to correspond to Goffman's sense of normality in a form of constant control over a bodily behavior, creating some conditions of "normality" and relative safety of an individual, allowing them to safely carry on with a given activity, paying only some superficial attention to the stability of the surroundings (Goffman 1972:248). By creating appearances of normality, the bearer of the discrediting characteristic appears to be making efforts to omit this characteristic, concentrating on recognizing and organizing the course of interaction in such a way as to make their stigma as little insistent as possible (cf. Goffman 1963:145). At the same time, the "oversensitivity" revealed in the interactions seems to drive the mechanism of stigmatization, differentiating it into potential stigmatization (to some extent "provoked" by the hosts through hyper-correctness, delicacy, sensitivity) and actual stigmatization, in fact, directed towards them by clearly disconnected normals.

\section{Strategy for Covering the Stigma}

Another strategy implemented as a part of stigma annulment work, apart from skipping, is the covering strategy. It is no longer only about the discreditable, but also about the discredited persons, appropriately situating the interactions at the meeting point of visibility and obtrusiveness of stigma (Goffman 1963:143). As Goffman writes, "persons who are ready to admit possession of a stigma (in many cases because it is known about or immediately apparent) may nonetheless make a great effort to keep the stigma from looming large. The individual's object is to reduce tension, that is, to make it easier for himself and the others to withdraw covert attention from the stigma" (Goffman 1963:124). It is, therefore, a matter of diminishing the importance of stigma or diverting attention from it. The following tactics are adopted within the described strategy: opposing trait tactic and dominance tactic.

In the case of the opposing trait tactic, parents of a child with a disability build interaction with normals by concentrating on the trait that is opposing (contrasting) to the discrediting one, thus trying to divert attention from the stigma that could dominate the encounter. They, therefore, look for specific attributes to balance their stigma. Such a significant feature is supposed to raise the social status, ennoble the individual, thus acting as a "smokescreen" for the stigma they possess. This could be, for example, emphasizing certain attributes of both parents and the child, while, at the same time, "masking" the child's disability (which is possible for a child whose dysfunction may be hidden), as stated in the following quote:

Actually, by the way, when we were away with my husband and Jarek [changed name], and he was still little at the time, and it was impossible to know by looking at the child that it was a disabled child, it somehow came out the same way as if we wouldn't say anything about it to the people we met. And we met a nice family, also with children, and they were even enchanted by Jarek that he was such a pretty boy with curls, so we wanted to keep it up, in fact, we simply didn't talk about our problems and we just enjoyed the moment when we could have felt like other parents. [i.18.03]

At the same time, in the construction of self-presentation, the tactic of domination gains on importance, which consists in dominating the course of inter- 
action by the bearer, who thus does not allow the stigma to be emphasized and "presented" in the foreground. An example is the emotional and aggressive reaction of parents in the form of an attempt to scream at the judge to "force" them to make the "right" decisions and thus avoid possible questions and discussions about stigma. In such a situation, Goffman speaks of an arrogant, even harsh, reaction, apart from defensive automatic switching-off (Goffman 1963:49-50). Such a range of behaviors sometimes reveals the bearer's losing control over the interaction, demonstrating the chaos and nervousness of entering into relationships. The interaction thus perceived by the bearers of stigma is, at the same time, interpreted by normals as a source of uncertainty, showing the bearer as a person struggling with extreme emotions and behaviors, embedding their interactions in the context of mixed social situations.

I try not to get too mad, as I explain to myself that I have been through so much that I already have some experience and I can feel the situation and somehow respond to it properly. But, it happens that I lose my temper and I'm overwhelmed, and it happens that I use a little hotheaded character as a smokescreen. I know how to be suave and nice, but I can also respond a little more sharply and strongly so the people simply focus on me and not on my child. [i.17.08]

Summing up the work over the annulment of stigma (skipping and covering), it is worth mentioning that if an individual seeks for a kind of separation, not assimilation, they may discover that they use their enemies' language and style out of necessity (Goffman 1963:138), which paradoxically leads to the strengthening of the stigma. At the same time, the bearer blocking out the harm from the normals starts to become more like them in their behavior.

\section{The Work over Highlighting the Stigma}

In addition to the work of the annulment of stigma, there is the work of highlighting it, otherwise manifesting the stigma. This is the work intended to purposefully reveal and highlight the stigma. The work over highlighting the stigma consists of the efficient manipulation of the stigma in order to manifest it, to flash it around, to expose it where the situation (interest) requires. Parents, seeing the benefits of the disclosure of the stigma, decide to use it in a specific interest, by efficiently manipulating their image according to their needs and circumstances. Examples of the work over highlighting the stigma are the construction of self-presentation of the poor/wronged, clumsy/naive, or chosen/strong. All of the strategies mentioned above are resorted to by the parents of children with disabilities, both those who act in a fully conscious and benefit-oriented (calculating) manner, as well as resulting from the actual life situation and confirming the actual mental and social status.

\section{Constructing the Self-Presentation of the Poor/ Wronged}

Construing the self-presentation of the poor/wronged was of particular importance in building the image of the parents of children with disabilities, who took on a more or less unconsciously defensive position in their interactions with others. But, at the same time, they are emphasizing the difficulties of life and everyday problems, which sometimes even takes on the form of a stirring of various kinds of ailments. It was about properly presenting the self (fairly) as one who should be supported because of their social status. The tactics used to construct the self-presentation of the poor/wronged include the tactics of telling a story about harm and the tactics of playing a poor person. 
The tactic of a story about harm is to present the life story to the interactional partners in a way that emphasizes the adversities and obstacles a parent of a child with a disability (potentially) encounters. While such a narrative may involve authentic experiences and accumulated difficulties, which a parent of a child with disabilities is exposed to, it may also be the result of well thought-out ways of expressing and highlighting the problems involved in having a child with a disability to obtain specific benefits (e.g., various forms of support).

You see, I have such a situation that it's even hard to talk about it. But, it's nothing when compared to my friend because she has a child that doesn't move at all, so imagine how she has to do everything with him, and how much it burdens her physically and mentally. But, each of us, parents of children with disabilities, has our own problems and difficulties to deal with on a daily basis. [i.17.08]

In turn, as part of the tactic of playing a poor person, the parents presented themselves (personally and in relation to the situation in life) as poor in a literal, but also symbolic sense-as being wronged by fate. Sometimes this was accompanied by appropriate staging and deliberately selected attributes associated in a stereotypical way with poverty (usually appropriate clothing, used according to the situation and needs, e.g., during a visit to a given institution). In this way, they were part of the social image of "disability," which, in their opinion, was to make it easier to obtain external support.

It is a bit annoying that such a stereotype of the mother of a disabled child is that she is a person who can be neither well-dressed nor well cared for, but should only be like the Polish Mother. I'm sorry to say this, but it often looks like that when you look better, oth- ers immediately think that you have no problems and difficulties in life. That is why I will tell you that if you want to make a good "impression," that is, one that wouldn't be too appealing to anyone, it's best to choose an outfit that's not weather-related, but for the circumstances of what you want to do at the moment and I'm not thinking about the opera right now [laughter], but, for example, about an office or institution. [i.19.09]

\section{Constructing the Self-Presentation of the Clumsy/Naive}

Another strategy in the work on highlighting the stigma is to construct the self-presentation of the clumsy/naive with the help of playing clumsy tactics. This tactic is used when it allows a parent of a child with a disability to benefit from the specific advantages of having their stigma. Playing incompetent was one of the adaptation strategies for parents to cope with the situation. Then, playing clumsy relieves the parent from having to explain a lot of uncomfortable things, and also makes it easier to handle various (e.g., official) matters.

I know such [parents] who don't like sharp-witted, but they can do everything and they cope well. But, in front of others they play the poor who can't deal with anything. Sure, there are such, but there are also a lot of people who just made a way of life out of acting so. [i.17.02]

By using this tactic, the parent of a child with a disability has the opportunity to deal with situations that may cause them some real difficulties (e.g., in official matters) and thus reduce the accompanying feeling of uncertainty in dealing with institutions or their representatives. It sometimes happens that such a tactic served to avoid responsibility for the 
actions taken while trying to remain "blameless" in a situation where a given type of conduct may have negative consequences or may have been associated with certain ailments (e.g., when the deadline for dealing with a particular case was not met, which could have resulted in certain sanctions). In this way, they used how the "normals" perceived the bearers of stigma, designing the presentation of themselves as uninformed, pretending not to know or understand what is going on (Goffman 1963).

\section{Constructing the Self-Presentation of the Chosen/Strong}

The third example of highlighting the stigma is the construction of the self-presentation of the chosen/ strong, which means attributing to oneself the role of the "chosen by fate" because they fulfill the difficult "task entrusted to them (by God)" of being a parent of a child with a disability. This strategy is implemented by means of contrasting tactics, that is, striving to achieve a contrast with the category of people who are to serve as a comparative group, in comparison with which the stigmatized person is to obtain a better, because higher, social status (Goffman 1963). In the case of parents of children with disabilities, this meant that they compared themselves with parents of healthy children, recognizing that their situation was not only objectively more difficult and complicated, but it also required much more energy and commitment. Hence, as some of the parents used to say, "not everyone would be able to cope with such hardship," which was reflected in the occasional circumstances of some parents leaving their children with disabilities in hospitals (right after birth) or care facilities. Therefore, those parents who have persisted in their attitude of maintaining and caring for their disabled daughter or son emphasized their commitment, but often also their above-average ("superhuman") efforts, which, despite numerous adversities, they have managed to meet.

The kind of experiences I have, it's hard for me to say. It was a very hard time, so now I wonder how I managed to survive it at all. But, I was younger, I had more energy, so maybe it was easier. In any case, I don't wish such experiences on anyone because probably not everyone would be able to cope and come out of such situations. Because I will tell you that there are parents who give up at the very beginning, although I don't want to judge them either because it is an individual matter. [i.17.08]

Moreover, those parents emphasized that, in some way, they were designated by God or "anointed" by fate to bear the burden of care for a child with a disability. In this way, they highlighted the contrast between them and the parents of fully capable children, who, although "endowed" with a fully capable daughter or son, which, by the way, they considered to be the highest value, did not experience all those emotions, feelings, and, above all, did not have the opportunity to "test themselves," "pass the exam of the highest form of love," as they themselves did.

I say that we, the parents of disabled children, are the chosen ones, and we make up in excess during our lifetime, so that later on we can provide ourselves with a suitable place up there [laughter]. But, tell me, aren't those efforts and everything that comes with them the best capital for the eternal life [laughter]. [i.19.07]

This way of presenting oneself and the situation was a form of ennoblement, recognition, and highlighting the positive aspects of the whole situation: superhuman perseverance ("which not everyone 
has") and a kind of "distinction" by fate guaranteeing that "their reward awaits them [in heaven]."

Summing up, the described course of interaction is of great symbolic significance as it allows the discreditable individual to give themselves a sense of control over the situation, which, in turn, can be translated into the experience of a sense of interactional activity that the individual can design for certain areas of the more uncertain institutionalized public space. In this sense, the strategies undertaken by parents of children with disabilities can be looked at from the perspective of partners maintaining a certain order of interaction, the disruption of which could lead to a kind of interpretative confusion (cf. Garfinkel 1967). In this way, parents attempt to take symbolic control over certain parts of the space by means of conducting the interaction taking place on their own rules of the game, which is often achieved by means of a certain type of capital that they have at their disposal for such a circumstance (such capital can be, among others, the ability to cope with stress or having adequate resources of "life" experience).

\section{Work over the Suspension of Stigma}

In addition to the work over the annulment and highlighting the stigma, the work on suspending the stigma can also be distinguished. This work seems to be a kind of compilation of the two previous ones, consisting of temporary, periodical suspension (annulment) and "activation" of (highlighting) the stigma, depending on the situation. In the case of parents of children with disabilities, the work of suspension is to refrain from emphasizing the discrediting feature, or at least "not to flash it around" at a given moment. In such a context, a hold-up tactic is employed, used especially in building one's image in the form of relationship work. The suspension of stigma is revealed in an attempt to temporarily and occasionally (situationally) exploit the parent's ignorance of others having a child with a disability. A specific type of the closed context of consciousness (Strauss and Glaser 1974) applies here because it is not the environment that hides the truth from a given person, but it is this person who takes advantage of the fact of unconsciousness of the environment as to the feature (property) that they possess and do not reveal to others.

In my case, it was like, I was trying to get a job because after Janek was born [changed name], I couldn't go back to work for a long time, so I didn't say that I had a disabled child when I applied for work. In my case, fortunately, I had the support of my parents and I knew that I didn't need to have any preferential working conditions to care for my child. That's why I could afford such a ploy and didn't say anything about family problems. I was simply afraid that it might harm me when applying for a job, and yet employers look at private matters differently, so I was silent on this issue, hoping that if they get to know me at work and when I find myself there a little bit, then maybe I would say something about it, or that it would just come out at some point, but without any negative consequences for me. [i.19.02]

It is worth noting that in case of manipulating the stigma of "juggling" the image of the parent such activities often carry the risk of discovering a hidden disability, which may lead to stigmatization, from which they tried to escape, but also to exclusion and marginalization resulting from the loss of credibility. The disclosure of a disability can expose parents to constant attention to stigma, as well as it may trigger the excessive curiosity of the third parties, combined with the crossing of privacy bound- 
aries in formal situations. For this reason, parents of children with disabilities need to think carefully about how they will engage in active identity manipulation (Carey 2013:142), whether they will try to hide it and make their children consider themselves fully functional, or, vice versa, they will apply a policy of openness and transparency. Or, perhaps they will combine both strategies and use them depending on the context.

\section{Discussion}

Literature describing the situation of families with children with disabilities usually discusses the attitudes of parents, the values of married life, the atmosphere of coexistence in the family, the family's social structure, sometimes personality features of the parents, assuming that the greater the disruptions in the scope of these qualities of family life, the greater the disorders in the processes of raising disabled children and taking care over them. Such an analysis model fails to explain the complexity of the situation of families. What is more, such a model assumes that there is a close causative relationship between a child's disability and disorders in the social adjustment of parents. It is not sufficiently explained how it happens that disruptive behaviors are formed in a family bringing up a child with a disability, but also such behaviors that allow for effective social roles and enable parents to function properly in the context of changes taking place within the identity area.

While criticizing such analytical models of the functioning of families with disabilities, in the case of this research, an interactionist approach has been proposed. In this perspective, the social roles of the parents are being constantly produced in a reflective process of interpretation, and their implementation is not so much a simple application of the rules that the society suggests, but is creative in nature, associated with its active co-development in the processes of interpretation, creation, and modification (Hałas 1987). Based on the assumptions of the interactionist approach, identity is also created as part of the continuous process of establishing relationships between the individual and one's surroundings. In the process of defining oneself, the individual compares oneself with other people, noticing the similarities and differences. They also want to stress their individuality and distinctness. In this perspective, the human sense of identity is mainly related to their own existence, the feeling of distinctiveness from the surroundings, the internal cohesion, one's own value, autonomy, and independence (Piotrowski 1998).

Furthermore, such an approach allows the adopting of a more systematic perspective when looking at the whole family because it is clearly visible that there are mutual dependencies between the behaviors and feelings of family members; the emergence of changes in the behavior of one person in the family (e.g., due to having a disabled or sick child) impacts the situation of all its members, namely, the functioning of the family system as a coherent whole. Also, the functioning of such families is also affected by the system of the social environment's conditions, where the family with a child with a disability lives.

Unfortunately, due to misinformation and misunderstandings, people with disabilities and their families are often not considered equal or valued members of society. Dr. Martin Luther King, Jr. said: "As long as the mind is enslaved, the body can never be free." To paraphrase these words, we can say that as long as people are ashamed of who they are, they will never 
realize the true equality and freedom they want, and can, achieve. It is worth taking into account another, and, at the same time, relatively new, approaches related to disability, which is quite clearly resounding within the framework of the conducted research, namely, disability-pride movements. According to this approach, there is a great need to create a counter-culture, which teaches new values and beliefs and recognizes the dignity and value of all human beings. A direct response to this need is disability pride, which was defined as the acceptance and respect for the uniqueness of every person and seeing them as a natural and beautiful part of human diversity.

Therefore, the adopted research models enable us to look not only at the issue of stigmatization analyzed in this text, but also highlight a broader perspective referring to the issue of the whole life and the functioning of families with children with disabilities. In this way, instead of asking about the nature or essence of disability, it seems more important to ask the following questions: what it means to experience disability and how it is experienced? This is how we ask about how a certain context for the reality construct regarding the parents of children with disabilities is created. In such a perspective, the disability is not a fact the nature of which is to be discovered, but rather an experience that awaits to be described; a social and cultural creation composed of various experiences that await to be recognized (Podgórska-Jachimiak 2014:78).

\section{Conclusions}

The presence of a child with an intellectual disability exerts a multifaceted impact on the functioning of the family and can also be a source of complex emotions and experiences. The fact of the child's disability is usually related to the changes in the family's material situation, a change of its social situation, and the psychophysical situation of its members. The confrontation with the child's disability means, among other things, a reformulation of goals or changes in expectations connected with the birth of the offspring, which leads to the feeling of mental tensions and negative affective states. One form of adaptation of parents to such living conditions is the emergence and implementation of particular interactional actions and strategies. The research has shown that at the heart of the strategies and tactics that make up the interactive space existing between the parents of children with disabilities and their environment is the importance of the stigmatization process that takes place in the context of mixed social situations. For this reason, the parents of children with disabilities, as carriers of a discrediting characteristic, are often involved in mixed interactions. In this sense, the strategies taken by parents can be seen in the context of the metaphor of the self-defense tactics (of the family) that are adopted to manage stigma as part of a wider process of dealing with stigma.

For this reason, when planning the strategies for the everyday functioning (and thus presentation) of the family in an interactional space that goes beyond the safe hinterland of their private area, they exhibit great concern both towards managing its visibility (or openness) and in building justifications for taking specific actions to conceal it.

The parents of children with disabilities are, therefore, aware of the stigma, which tints the interactions they enter to increase the level of control over how they may unfold. From this position, they initially evaluate their interactional partner, deduce the identity assigned to them, and sketch a preliminary pattern of the interaction before it takes place. Such actions take place before the participants enter the interaction or refer to their interlocutor's mes- 
sage opening interaction with them, with the aim of strategically modifying the context of the encounter. The continuous censorship of its planned course takes into account the evaluation in terms of public expectations.

A huge part of the interactional work of parents of children with disabilities, therefore, takes place not as much in the course of the interaction itself. The dynamics of which are underpinned by participating in a mixed social situation (with one partner being cast as the stigmatized and the other as the stigmatizing). This happens when the person with the discrediting feature assumes that they will have to deal with the stigma attributed to them by their interlocutor(s), as in the mind (consciousness) of the person with the discrediting feature-in the

\section{References}

Aschbrenner, Kelly A. at al. 2010. "Subjective Burden and Personal Gains among Older Parents of Adults with Serious Mental Illness." Psychiatric Services 61(6):605-611.

Barnes, Colin and Geoff Mercer. 1997. Doing Disability Research. Leeds: The Disability Press.

Belzyt, Joanna I. 2005. Kontakt i komunikacja z osobami niepetnosprawnymi. Aspekty niewerbalne [Contact and Communication with People with Disabilities. Non-Verbal Aspects]. Torun: UMK Press.

Błeszyńska, Krystyna. 2001. Niepetnosprawność a struktura identyfikacji społecznych [Disability and the Structure of Social Identification]. Warsaw: Wydawnictwo Akademickie Żak.

Carey, Allison C. 2013. “The Sociopolitical Contexts of Passing and Intellectual Disability." Pp. 142-166 in Disability and Passing: Blurring the Lines of Identity, edited by J. Brune and D. J. Wilson. Philadelphia: Temple University Press.

Charmaz, Kathy. 2006. Constructing Grounded Theory. A Practical Guide Through Qualitative Analysis. Thousand Oaks, CA: Sage Publications. course of their interactions with themselves. This is the kind of work that can be described as a sort of preparation for initiating an interaction or responding to a message inviting an interaction. The purpose of such preparation is to increase one's sense of control over the course of potential interaction in the direction of protecting the bearer of the stigma from degradation.

Although the context of mixed social situations is only invoked at the time of the interaction-due to knowing one's stigma-the repeated participation of the parents of children with disabilities in interactions taking the form of mixed social situations makes the context of mixed social situations permanent and present beyond the ever-developing interactional order of social encounters.

Docherty, Julie and Kate Reid. 2009. “'What's the Next Stage?" Mothers of Young Adults with Down Syndrome Explore the Path to Independence: A Qualitative Investigation." Journal of Applied Research in Intellectual Disabilities 22(5):458-467.

Freedman Ruth I., Marty W. Krauss, and Marsha M. Seltzer. 1997. “Aging Parents' Residential Plans for Adults with Mental Retardation." Mental Retardation 35(2):114-123.

Garfinkel, Harold. 1967. Studies in Ethnomethodology. Los Angeles: Prentice-Hall.

Glaser, Barney G. 1978. Theoretical Sensitivity. Advances in the Methodology of Grounded Theory. Mill Valley, CA: The Sociology Press.

Glaser, Barney G. and Anselm L. Strauss. 1967. The Discovery of Grounded Theory. Strategies for Qualitative Research. Chicago: Aldine.

Goffman, Erving. 1963. Stigma. Notes on the Management of Spoiled Identity. Harmondsworth: Penguin. 
Goffman, Erving. 1972. Encounters. Two Studies in the Sociology of Interaction. Harmondsworth: Penguin University Books.

Hałas, Elżbieta. 1987. Społeczny kontekst znaczeń w teorii symbolicznego interakcjonizmu [The Social Context of Meanings in the Theory of Symbolic Interactionism]. Lublin: Redakcja Wydawnictw Katolickiego Uniwersytetu Lubelskiego.

Heller, Tamar and Catherine Keiling Arnold. 2010. "Siblings of Adults with Developmental Disabilities: Psychosocial Outcomes, Relationships, and Future Planning." Journal of Policy and Practice in Intellectual Disabilities 7(1):16-25.

Hodapp, Robert M. 2007. “Families of Persons with Down Syndrome: New Perspectives, Findings and Research and Service Needs." Mental Retardation and Developmental Disabilities Research Reviews 13(3):279-287.

Hodapp, Robert M., Laraine M. Glidden, and Ann P. Kaiser. 2005. "Siblings of Persons with Disabilities: Toward a Research Agenda." Mental Retardation 43(5):334-338.

Johnson, Eric D. 2000. "Differences among Families Coping with Nervous Mental Ill Adults: A Qualitative Analysis." American Journal of Orthopsychiatry 70:126-134.

Kościelska, Małgorzata. 1995. Oblicza upośledzenia [Faces of Handicap]. Warsaw: PWN.

Kroll-Smith, Steve and H. Hugh Floyd. 1997. Bodies in Protest: Environmental Illness and the Struggle over Medical Knowledge. New York: New York University Press.

Miltiades, Helen B. and Rachel Pruchno. 2001. "Mothers of Adults with Developmental Disability: Change over Time." American Journal on Mental Retardation 106(6):548-561.

Orsmond, Gael I. and Marsha M. Seltzer. 2007. "Siblings of Individuals with Autism or Down Syndrome: Effects on Adult Lives." Journal of Intellectual Disability Research 51(9):682-696.

Orsmond, Gael I. et al. 2003. "Behavior Problems in Adults with Mental Retardation and Maternal Well-Being: Examination of the Direction of Effects." American Journal on Mental Retardation 108(4):257-271.

Phyllis, Solomon and Jeffrey Draine. 1995. “Subjective Burden among Family Members of Mentally Ill Adults: Relation to Stress, Coping, and Adoption." American Journal of Orthopsychiatry 65(3):419-427.

Piotrowski, Andrzej. 1998. Ead interakcji. Studia z socjologii interpretatywnej [The Order of Interaction. Studies in Interpretative Sociology]. Lodz: Wydawnictwo UŁ.

Podgórska-Jachnik, Joanna. 2014. Praca socjalna z osobami $z$ niepetnosprawnościa $i$ ich rodzinami [Social Work with People with Disabilities and Their Families]. Warsaw: Centrum Rozwoju Zasobów Ludzkich.

Seltzer, Marsha M., Frank Floyd, and Jan Greenberg. 2005. “Life Course Impacts of Mild Intellectual Deficits." American Journal on Mental Retardation 110(6):452-468.

Strauss, Anselm L. and Juliet Corbin. 1990. Basics of Qualitative Research: Techniques and Procedures for Developing Grounded Theory. Thousand Oaks, CA: Sage.

Strauss, Anselm L. and Barney Glaser. 1974. Chronic Illness and the Quality of Life. Saint Louis, MO: Mosby.

Strauss, Anselm L. et al. 1985. Social Organization of Medical Work. Chicago: University of Chicago Press.

Zakrzewska-Manterys, Elżbieta. 2010. Upośledzeni umysłowo. Poza granicami człowieczeństwa [Mentally Handicapped. Beyond Humanity]. Warsaw: Warsaw University Press.

\section{Citation}

Niedbalski, Jakub. 2021. "Life Strategies of the Parents of Children with Intellectual Disabilities in the Context of Mixed Social Situations." Qualitative Sociology Review 17(1):176-194. Retrieved Month, Year (http://www.qualitativesociologyreview.org/ENG/ archive_eng.php). DOI: http://dx.doi.org/10.18778/1733-8077.17.1.11 